\title{
An Experimental Investigation of Vapor Generator Characteristics in a Low-pressure Turbine Engine
}

\author{
Pattanachok Saiai ${ }^{*}$, Sumpun Chaitep ${ }^{1}$, Damorn Bundhurat ${ }^{1}$ and Pipatpong Watanawanyoo ${ }^{2}$ \\ 'Department of Mechanical Engineering, Faculty of Engineering, Chiang Mai University, Chiang Mai, 50200, \\ Thailand; pattanachok.s@gmail.com,svmpvn@gmail.com,damornb@yahoo.com \\ 2Mechanical Engineering Program, College of Engineering, Rangsit University, Pathumthanee, 12000, \\ Thailand; tum1879@hotmail.com
}

\begin{abstract}
This paper proposes an experiment using a vapor generator for a low-temperature heat source to drive a turbine engine. The system consists of a heat source to heat the water in the vapor generator apparatus, and thus heating the water in the system of the working fluid increases the vapor turbine driving force. In this study, HCFC-141b is used as a working fluid in the system because it has better thermo-physical properties, is a non-flammable liquid, is non-destructive to the atmosphere, and has a high molecular mass and low boiling point. The experimental conditions comprised operating temperatures of 70 to $100^{\circ} \mathrm{C}$ and a starting temperature of $30^{\circ} \mathrm{C}$. The variables studied were the heating rate of vapor generator, mass flow rate of the working fluid flow through the vapor generator, inlet and outlet temperatures and pressures through the flow vapor generator, and power output. These results were recorded to determine the performance and thermal efficiency of the vapor generator in the vaporized for driving the turbine. The results of this study show the potential of using a vapor generator for small-scale electricity production.
\end{abstract}

Keywords: Low-Temperature Heat Source, Low-pressure Turbine, Organic Rankine Cycle, Vapor Generator

\section{Introduction}

In recent years, the escalating consumption of fossil fuels has caused many serious environmental problems, such as global warming, ozone layer destruction, and atmospheric pollution. New energy conversion technologies are required to utilize energy resources suitable for power generation without causing environmental pollution. Low-temperature heat sources are considered as candidates for the new energy sources. Solar heat, waste heat, and geothermal energy are typical examples of low-temperature heat sources with their available temperatures ranging between 60 to $200^{\circ} \mathrm{C}{ }^{1}$. The use of such lowtemperature heat sources as an alternative energy source to generate electricity has long been investigated using power turbine cycles. The temperature of the exhaust from most industrial processes and power plants is less than $370^{\circ} \mathrm{C}$. If this kind of waste heat is released into the environment directly, it leads to not only waste but also heat pollution to the environment ${ }^{2,3}$.

The Organic Rankine Cycle (ORC) system exhibits great flexibility, high safety, and low maintenance requirements in recovering this grade of waste heat. By integrating the ORC into energy systems, such as power plants, the use of low-grade energy to generate high grade energy (power) could be achieved, easing the power burden, and enhancing system efficiency ${ }^{4}$. Since the ORC consumes virtually no additional fuel, for the same added power, the emission of environmental pollutants such as Carbon Dioxide $\left(\mathrm{CO}_{2}\right)$, Sulphur Dioxide $\left(\mathrm{SO}_{2}\right)$, and so on will be decreased. Moreover, according to the local demand, the exhaust heat exiting from the ORC could be

*Author for correspondence 
further utilization such as absorption chillers for supplement of cooling capacity. Little attention has been given to these systems because of the low thermal efficiency of the Rankine cycles which are operated at low temperatures and low pressure. Such systems, however, have a simple structure, can be constructed at low cost, and apply existing technologies ${ }^{5,6}$. This application system is an appealing option for remote, low power applications. One of the main advantages of ORC lies in mechanical simplicity. As mentioned before, ORC typically consist of a single stage expander which consists of a single rotating component for the entire system. For the past several decades, thousands of ORC have been developed and used for remote terrestrial applications with power outputs ranging from $1 \mathrm{~kW}$ to $1 \mathrm{MW}$. A few examples of remote applications that have used efficient, reliable, unattended ORC power sources include communication stations, data gathering buoys, satellite communication power supplies, as well as irrigation pumps, air conditioners, and turbo-generators ${ }^{7}$.

This purpose of study was designed and developed for a low-pressure turbine engine on the ORC. The performance of the system was investigated with a turbine output system with a turbine power output of less than $0.1 \mathrm{~kW}$. In order to realize such a system, an efficient and low-cost turbine is indispensable. In this study, an experimental system is developed using a vapor generator to produce vapor to drive the micro-radial turbine, which is one of the possible type for the expander. Other commercially available components were also used. The system was equipped with a heat source with a temperature range of 70 to $100^{\circ} \mathrm{C}$ and a cold source with a temperature range of 5 to $15^{\circ} \mathrm{C}$. The proposed system was capable of producing a turbine power output of approximately $1.6 \mathrm{~W}$. A fundamental experiment was conducted and the turbine performance was investigated for various rotation speeds. Furthermore, the turbine and thermal efficiencies of the proposed system were calculated and analyzed.

\section{Material and Methods}

\subsection{Cycle Thermodynamic Simulation}

In this research, the thermodynamic simulation to determine the optimum design and operating condition carried out by thermodynamics analysis. The power cycle model system is determined from the effects of heat source at evaporator, mass flow rate of working fluid, turbine inlet pressure, and turbine inlet temperature, whereas the performance is then can be determined. The overall efficiency, which can evaluate the system performance, is selected as the target for optimizing system design by computer program.

The outline of the procedure involves the system to determine the cycle efficiencies as well as irreversibility for simple Rankine cycle diagram; presented in Figure 1 the cycle simulation model in this research uses assumptions as following.

- The operation of the cycle is in the steady state conditions.

- The power cycle system is reversible process.

- The working fluid is saturated vapor at the inlet turbine and is saturated liquid at the condenser exit.

- The turbine and pump operates at isentropic process.

- No pressure drops in the vapor generator, condenser, and pipe.

- Cycle simulation used spreadsheet from Microsoft Excel

\subsection{Organic Rankine Cycle Apparatus}

The system's operation is described briefly. The thermal energy produced from the heat source by the vapor generator, is shown in Figure 2, it preheated and vaporized the working fluid in this system. The superheated vapor or saturated vapor is fed to drive to the turbine, where the generated mechanical output work was directly coupled for an electric generator. The micro-turbine is in a work shaft running as radial flow type. The sub-cooled liquid at the condenser outlet is pressurized by the pump. In the case of working fluid, after the expansion from the turbine is assigned to situate in the superheated vapor region. As

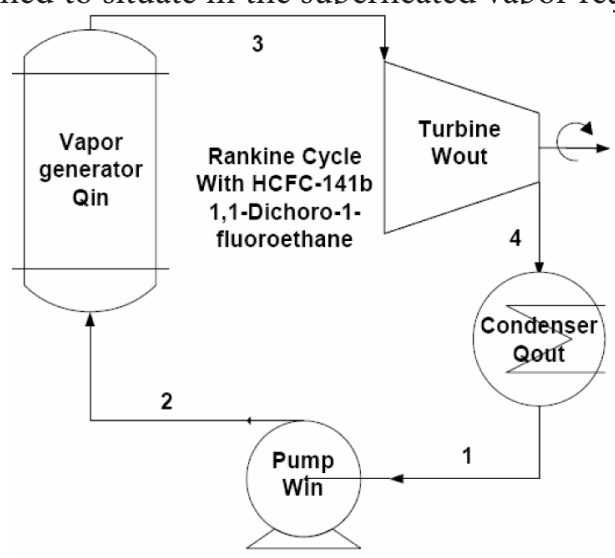

Figure 1. Schematic presentation of numerical simulation and apparatus of organic Rankine cycle ${ }^{8-10}$. 


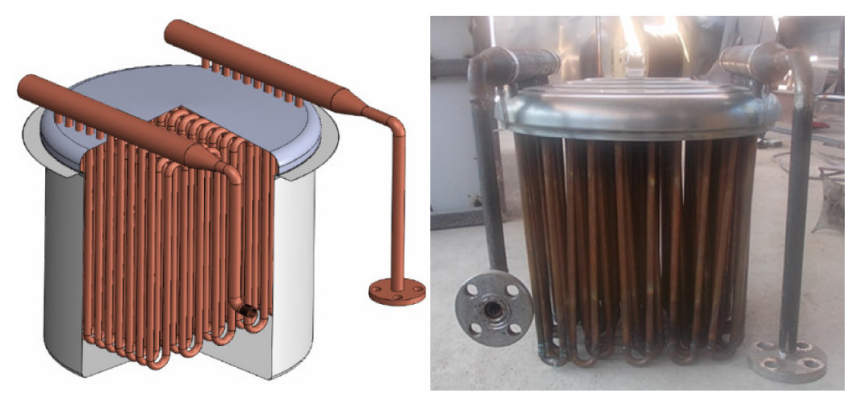

Figure 2. The thermal energy produced from the heat source by the vapor generator unit.

the temperature of the superheated vapor at the turbine outlet is more than that of the liquid at the inlet of the vapor generator, it is possible to improve the thermal efficiency of the cycle by adding in a regenerator. The temperature of the vapor generator being fed can be further increased by bleeding working fluid from the turbine and mixing it with the vapor generator feed in a direct contact heater. Simultaneous regeneration and turbine bleeding improves the thermal efficiency of the power cycle. For a system with turbine bleeding and regeneration, an internal heat exchanger and a direct contact heater are incorporated into the simple Rankine cycle.

\subsection{Experimental Conditions}

This work uses HCFC-141b (1,1-Dichloro-1fluoroethane) as the working fluid in the system, because of its better thermo physical properties, nonflammable liquid, non-destructive to the atmosphere, high molecular mass and a low boiling point. Figure 3 shows the test rig components and experimental flow diagram. The experiment was carried out the four test conditions. The heat inputs of the vapor generator are $70,80,90$, and $100^{\circ} \mathrm{C}$. Temperature, pressure, torque, and rotation shaft speed can be measured by measuring device. The performance estimation of the ORC system is determined from the experiment data which comparing the outlet turbine, pressure, working fluid flow rate, and inlet and outlet temperatures. Following example information is the input/output result obtained from an experiment setting at generator and condenser i.e., $90^{\circ} \mathrm{C}$ and $30^{\circ} \mathrm{C}$ respectively.

1. Vapor generator temperature and pressure $=90^{\circ} \mathrm{C}$, $537.67 \mathrm{kPa}, \mathrm{Q}_{\mathrm{VG}, \mathrm{i}}=70.36 \mathrm{~kW}$

2. Condenser temperature and pressure $=30^{\circ} \mathrm{C}, 94.17$ $\mathrm{kPa}, \mathrm{Q}_{\mathrm{C}, \mathrm{o}}=60.27 \mathrm{~kW}$
3. Isentropic turbine and pump efficiency $=85 \%$

4. Vapor generator unit sizing $A_{i, d}=1.517 \mathrm{~m}^{2}, V_{i, d}=$ $0.00406 \mathrm{~m}^{3}$

5. Condensing unit sizing $A_{i, d}=0.773 \mathrm{~m}^{2}, V_{i, d}=0.001852 \mathrm{~m}^{3}$

6. Hot side pinch $=10^{\circ} \mathrm{C}$ and cold side pinch $=20^{\circ} \mathrm{C}$

7. Working fluid mass flow rate are $122.6-128.9 \mathrm{~kg} / \mathrm{h}$

\section{Results and Discussion}

From the numerical simulation and experimental results, the temperature of the vapor generator increases corresponding to the heat increasing efficiency of the system. This result follows from the Carnot cycle efficiency. The thermal efficiency is increased when the temperature of the heat source is increase.

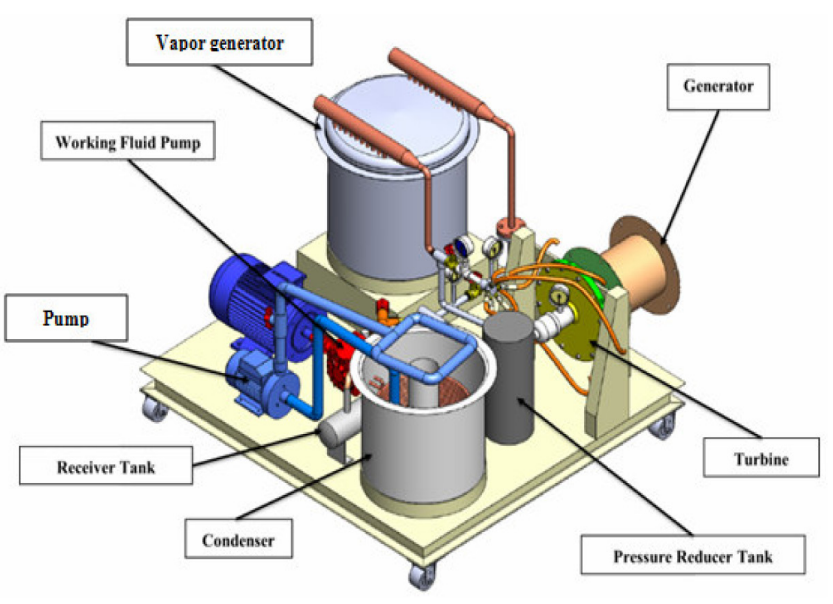

(a)

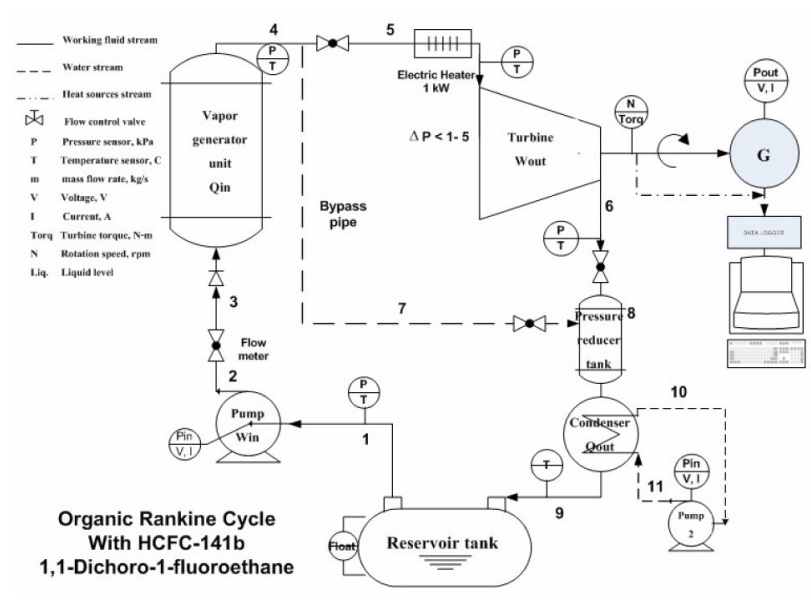

(b)

Figure 3. (a) The ORC system and (b) Schematic diagram of the configuration components. 
Table 1 shows the theoretical analysis of the thermal efficiencies of the system for the heat source temperature difference between 70 and $100^{\circ} \mathrm{C}$. The theoretical turbine power was $1.16 \mathrm{~kW}$, whereas the thermal efficiency for the temperature heat source of experiment is show in the Table 2. In the case of $\mathrm{T}_{\mathrm{s}}=100^{\circ} \mathrm{C}$, the thermal efficiency was $14.15 \%$.

These results imply that the pressure difference dominates the turbine torque and power output. In other words, and appropriate working fluid that can maximize the pressure difference for a particular temperature difference should selected.

Table 2. lists the maximum power output condition for temperature heat source were $72.4,82.3,90.7$, and $96.1^{\circ} \mathrm{C}$, the maximum turbine power output were 0.81 , $1.03,1.32$, and $1.60 \mathrm{~W}$ respectively, while the theoretical turbine power output was $1.16 \mathrm{~kW}$. The thermal efficiency of system for the temperature heat source in the Table 2 are as follow, in the case of $\mathrm{T}_{\mathrm{s}}=96.1^{\circ} \mathrm{C}$ the measure thermal efficiency was $0.019 \%$, while the theoretical thermal efficiency was $16.52 \%$. It can be seen that experimental thermal efficiency is relatively less than of the theoretical thermal efficiency.

Figure 4 show the dependence of the turbine output on the temperature inlet temperature under the superheated vapor conditions at the turbine inlet temperature of vapor generator. In the case of each temperature heat source, the turbine output increases proportionally with the increase in the temperature heat source. These results can be understood as follows. The theoretical turbine efficiency will be increase as temperature heat source, turbine inlet temperature, pressure ratio, and only the mass flow rate increases proportionally as the compact vapor generator input increases. Accordingly the relationship between the turbine output and the temperature heat source is obviously expressed. These simulation results show that HCFC-141b gives the good performance, even though the system uses low temperature heat sources.

Figure 5 show the effects of vapor generator temperature $\left(\mathrm{T}_{\mathrm{VG}}\right)$ on the heat rate of vapor generator and the turbine output on mass flow rate of working fluid of $112 \mathrm{~kg} / \mathrm{h}$, while the temperature heat source at the vapor

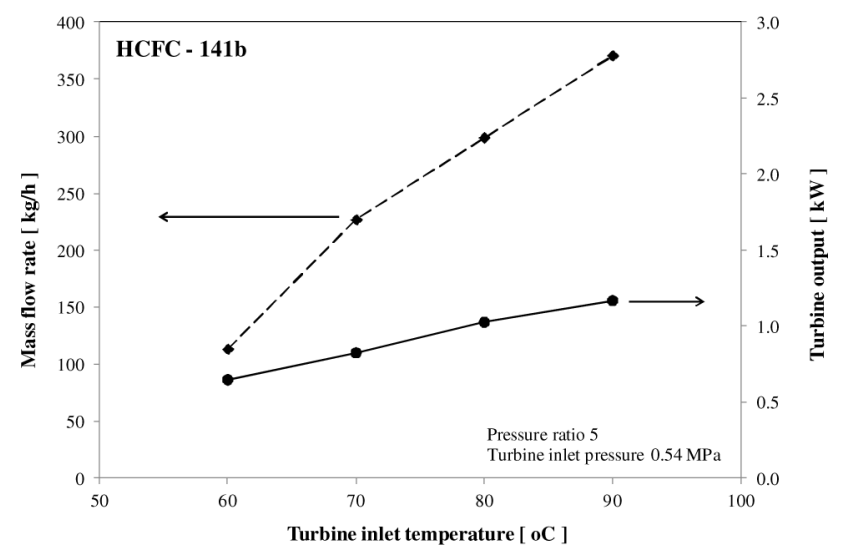

Figure 4. The effects of heat source temperature on the turbine inlet mass flow rate and the turbine output.

Table 1. The results of the numerical simulation (Theoretical analysis)

\begin{tabular}{cccccccccc}
\hline $\mathrm{T}_{\mathrm{s}}$ & $\mathrm{T}_{\mathrm{VG}, \text { in }}$ & $\mathrm{T}_{\mathrm{VG}, \text { out }}$ & $\mathrm{Q}_{\mathrm{VG}}$ & $\mathrm{Q}_{\text {Cond }}$ & $\mathrm{W}_{\mathrm{p}}$ & $\mathrm{W}_{\mathrm{T}}$ & $\mathrm{W}_{\text {net }}$ & $\eta_{\text {th,Rankine }}$ & $\eta_{\text {th,carnot }}$ \\
\hline${ }^{\circ} \mathrm{C}$ & ${ }^{\circ} \mathrm{C}$ & ${ }^{\circ} \mathrm{C}$ & $\mathrm{kW}$ & $\mathrm{kW}$ & $\mathrm{kW}$ & $\mathrm{kW}$ & $\mathrm{kW}$ & $(\%)$ & $(\%)$ \\
70 & 30 & 60 & 7.56 & 6.93 & 0.004 & 0.64 & 0.63 & 8.38 & 9.00 \\
80 & 30 & 70 & 7.77 & 6.94 & 0.006 & 0.83 & 0.82 & 10.61 & 11.66 \\
90 & 30 & 80 & 7.97 & 6.96 & 0.008 & 1.01 & 1.01 & 12.63 & 14.16 \\
100 & 30 & 90 & 8.17 & 7.00 & 0.011 & 1.17 & 1.16 & 14.15 & 16.52 \\
\hline
\end{tabular}

Table 2. The experimental results and performance of maximum turbine output condition

\begin{tabular}{lcccccccc}
\hline $\begin{array}{l}\mathrm{m}_{\mathrm{f}} \\
\mathrm{kg} / \mathrm{h}\end{array}$ & $\begin{array}{c}\mathrm{T}_{\mathrm{s}} \\
{ }^{\circ} \mathrm{C}\end{array}$ & $\begin{array}{c}\mathrm{P}_{\mathrm{r}} \\
-\end{array}$ & $\begin{array}{c}\mathrm{Q}_{\mathrm{v}} \\
\mathrm{kW}\end{array}$ & $\begin{array}{c}\text { Speed } \\
\text { RPM }\end{array}$ & $\begin{array}{c}\text { Torq } \\
\text { N.m }\end{array}$ & $\begin{array}{c}\mathrm{P}_{\max } \\
\mathrm{W}\end{array}$ & $\begin{array}{c}\eta_{\text {svs }} \\
-\end{array}$ & $\begin{array}{c}\eta_{\mathrm{cnt}} \\
-\end{array}$ \\
\hline 122.6 & 72.1 & 1.10 & 5.01 & 387 & 0.0158 & 0.81 & 0.016 & 10.0 \\
124.2 & 82.1 & 1.11 & 5.77 & 504 & 0.0184 & 1.03 & 0.018 & 11.1 \\
129.3 & 91.3 & 1.16 & 6.93 & 482 & 0.0208 & 1.32 & 0.019 & 12.6 \\
128.9 & 96.9 & 1.15 & 8.32 & 533 & 0.0232 & 1.60 & 0.019 & 14.8 \\
\hline
\end{tabular}




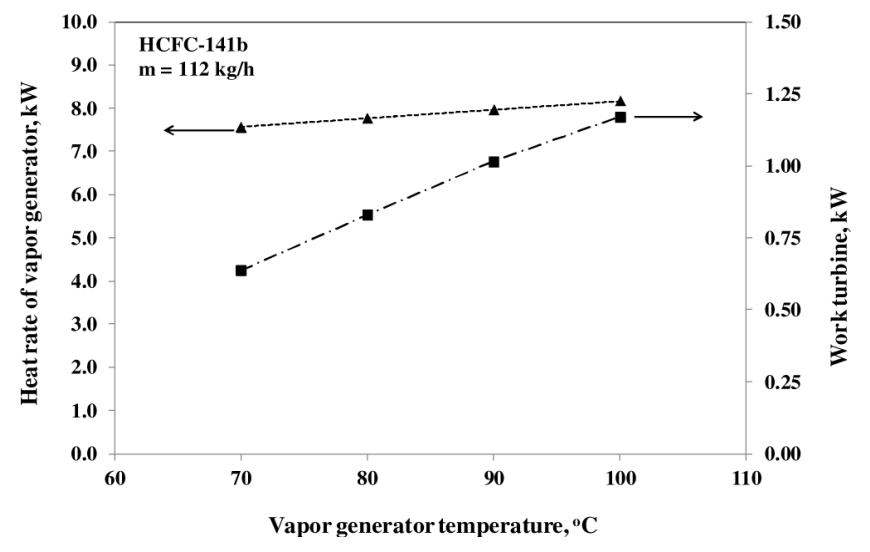

Figure 5. The effects of vapor generator temperature on the turbine inlet mass flow rate and the turbine output.

generator is fixed at $70^{\circ} \mathrm{C}$ to $100^{\circ} \mathrm{C}$. As for the case of $\mathrm{T}_{\mathrm{VG}}=100^{\circ} \mathrm{C}$, the turbine output increases as the mass flow rate decreases. Conversely, it only slightly decreases in the case of TVG $=70^{\circ} \mathrm{C}$. Thus, turbine inlet temperature and the turbine inlet mass flow rate should be increased to raise the turbine output. In this simulation, however, turbine inlet temperature increases as the mass flow rate decreases, or the mass flow rate increases as turbine inlet temperature decreases. It is therefore understood that the turbine output decreases when the mass flow rate in the turbine inlet decreases rapidly. If a working fluid with a low latent heat is used, the saturated vapor at the turbine inlet would give the good operating conditions.

Figure 6 presents the dependency of the turbine inlet temperature on the cycle efficiency for heat source temperature difference between $70^{\circ} \mathrm{C}$ to $100^{\circ} \mathrm{C}$ of $\mathrm{HCFC}$ 141b. These results tell us the characteristics of each temperature heat source and the effect of the pressure ratio. The cycle efficiency of each turbine inlet temperature increases as pressure ratio rises, and working fluid has a good efficiency. Therefore raising the turbine inlet temperature for the case of using HCFC-141b give high system performance.

Figure 7 shows the characteristic of turbine torque and turbine output when the temperature heat source between $72.4^{\circ} \mathrm{C}$ to $96.1^{\circ} \mathrm{C}$ as a function of turbine rotation speed. The rotation speed, torque and maximum power increased as temperature heat sources increased. In the heat source temperature is $96.1^{\circ} \mathrm{C}$ the maximum torque and maximum power reached $46.5 \mathrm{~N} . \mathrm{mm}$ and $1.60 \mathrm{~W}$, respectively; similar results were obtained the cases of temperature heat source (a) $72.4^{\circ} \mathrm{C}$, (b) $82.3^{\circ} \mathrm{C}$, and (c) $90.7^{\circ} \mathrm{C}$. The maximum turbine torque increment was

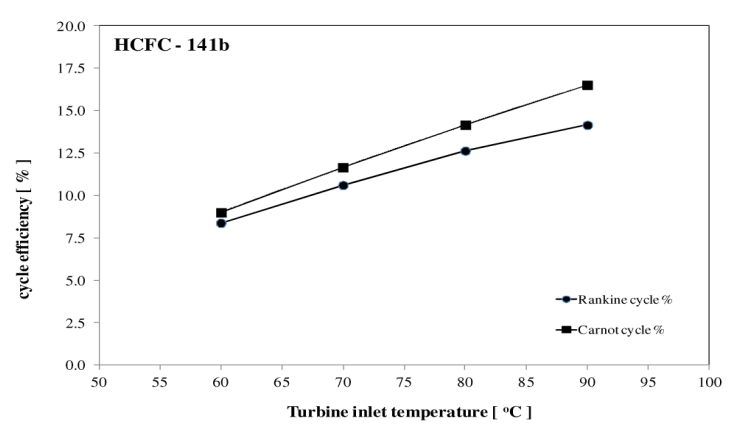

Figure 6. Relationship between turbine inlet temperatures with cycle efficiency.

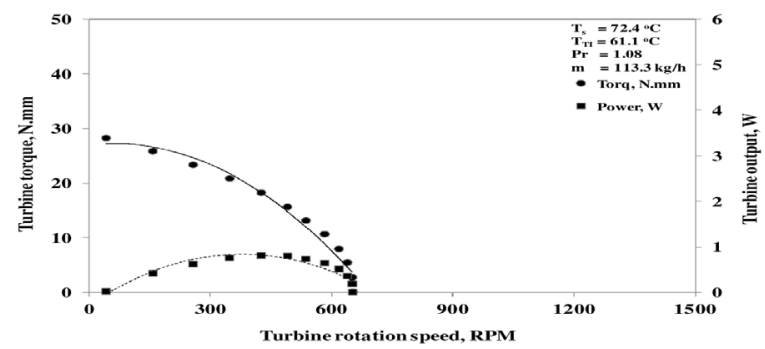

(a)

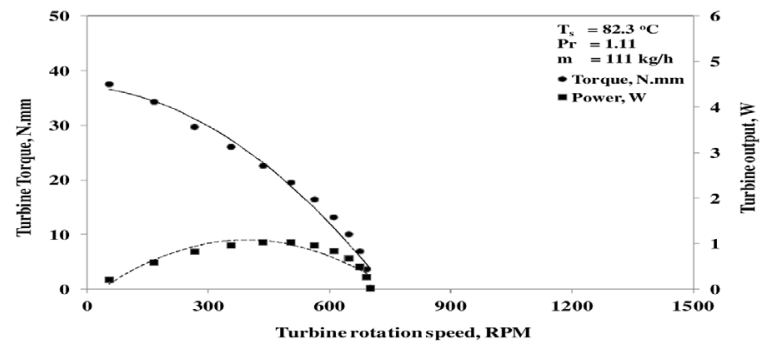

(b)
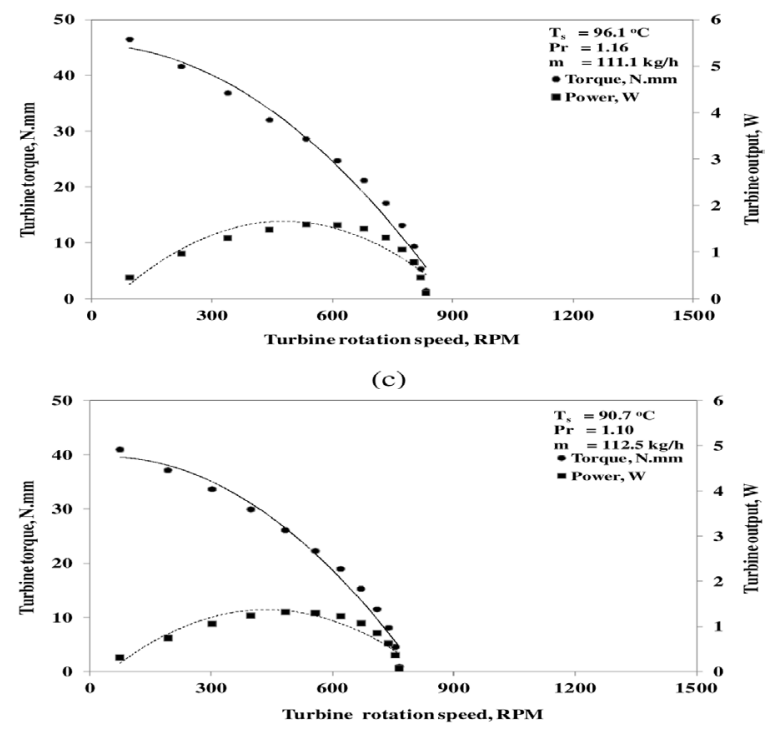

(d)

Figure 7. Relationship between turbine torque, turbine output and rotation speed in the cases of temperature heat source (a) $72.4^{\circ} \mathrm{C}$, (b) $82.3^{\circ} \mathrm{C}$, (c) $90.7^{\circ} \mathrm{C}$ and (d) $96.1^{\circ} \mathrm{C}$. 
caused by pressure difference pressure ratio between the turbine inlet and outlet in the case of small system.

Figure 8 shows relationship between turbine output and pressure ratio dependence on the temperature heat source at a compact vapor generator under the superheated vapor at the turbine inlet. In the case of each working fluid mass flow rate, the turbine output increases proportionally with the increase in the vapor generator temperature input. These results can be described as follows, the turbine output is inlet temperature while set as pressure ratio are constant, and only the mass flow rate increases proportionally as the vapor generator input increases. Accordingly the relationship between the turbine output, pressure ratio versus the temperature heat source input are expressed as a linear straight line, however at different value of slopes. These experimental results tell us that working fluid gives the good performance, even though the low pressure turbine uses low temperature heat sources.

Figure 9 shows the characteristics of temperature heat source and when the working fluid is HCFC-141b. For

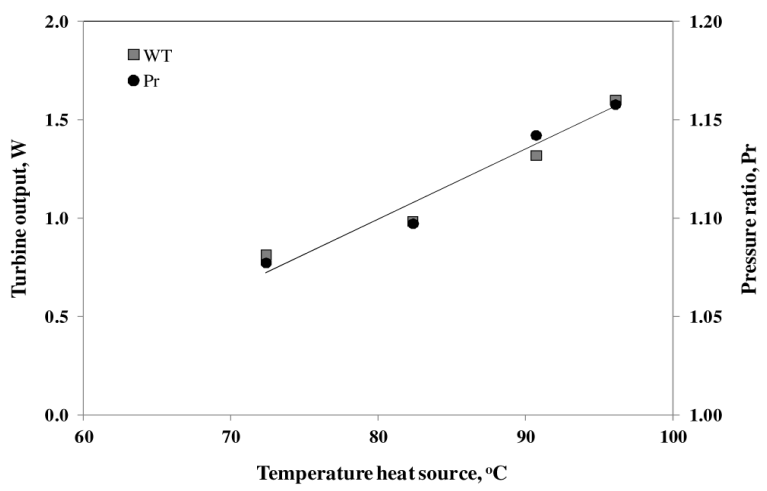

Figure 8. Relationship between temperature heat source, pressure ratio and turbine output.

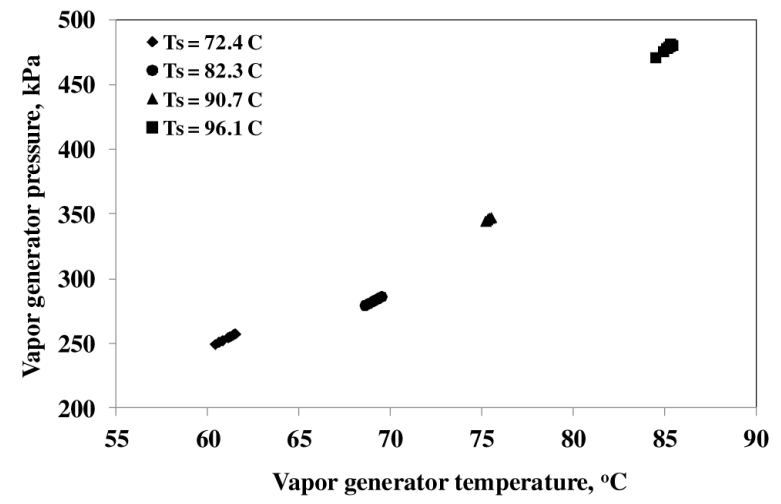

Figure 9. Relationship between temperature and pressure at the vapor generator. four cases of experimental setup, there are optimum operating conditions in the relationship between the turbine output and the rotation speed. These optimum operating conditions shift to a higher rotation speed as the vapor generator input rises. In the case of a vapor generator temperature, for example of $96.1^{\circ} \mathrm{C}$, the maximum outlet pressure at the vapor generator is $482.0 \mathrm{kPa}$. Whereas the temperature heat source at $70.4^{\circ} \mathrm{C}$, the maximum outlet pressure at the vapor generator is $257.5 \mathrm{kPa}$.

\section{Conclusions}

The possibilities of the low pressure turbine system working with HCFC-141b in this work have been investigated both of numerical analysis and experimental results. The numerical results show that the optimum working condition occurred when the minimum inlet temperature over the point of working fluid. If the latent heat of working fluid having low value, there are leading to gain the optimum running condition. In the aspect of turbine speed and power output of the turbine show that the working fluid can also improve the total system performance.

The ORC developed in this study may serve as a prototype for the further optimize of system. Further work show that system can be used with low-temperature of the heat source for the driving of a low pressure turbine in a micro electricity production unit.

\section{Acknowledgement}

The authors would like to thank the Graduate School, Faculty of Engineering, Chiang Mai University and Energy Policy and Planning Offices, Ministry of Energy for supporting the facilities and financial for this study.

\section{References}

1. Yamamoto T, Furuhara T, Arai N, Mori K. Design and testing of the Organic Rankine Cycle. Energy J. 2001; 26:239-251.

2. Badr O, O'Callaghan PW, Probert SD. Thermodynamic and thermophysical properties of organic working fluids for Rankine cycle engines. Applied Energy J. 1985; 19(1):1-40.

3. Badr O, Probert SD, O'Callaghan PW. Selecting a working fluid for a Rankine cycle engine. Applied Energy J. 1985; 21(1):1-42.

4. Borsukiewicz-Gozdur A, Nowak W. Maximising the working fluid flow as a way of increasing power output of 
geothermal power plant. Applied Thermal Engineering J. 2007; 27(11-12):2074-78.

5. Lui B, Chien K, Wang C. Effect of working fluids on organic Rankine cycle for waste heat recovery. Energy J. 2004; 29(8):1207-17.

6. Wei D, Lu X, Lu Z, Gu J. Performance analysis and optimization of Organic Rankine Cycle (ORC) for waste heat recovery. Energy Conversion and Management J. 2007; 48(4):1113-19.

7. Somayaji C. First and second law analysis of Organic Rankine cycle. [Ph. D. Thesis]. Mississippi State University, Mississippi, USA; 2008.

8. Saiai P, Chaitep S, Bundhurat D, Wattanawanyoo P. Performance assessment and thermal efficiency of a compact vaporizers used in low pressure turbine cycle. 2013 on International Conference of Alternative Energy in Developing Countries and Emerging Economies; 2013 May 30-31; Bangkok, Thailand: Pullman Bangkok King Power Hotel.

9. Saiai P, Chaitep S, Bundhurat D, Wattanawanyoo P. Performance assessment and thermal efficiency of a compact vaporizers used in low pressure turbine cycle. Energy Procedia; 2013.

10. Saiai P, Chaitep S, Bundhurat D, Na Lampang T, WattanawanyooP.Preliminarydesignandexperimentalstudies of low pressure turbine for organic Rankine cycle engine. National Conference on $12^{\text {th }}$ Heat and Mass Transfer in EquipmentandProcess;2013Mar14-15;ChiangRai, Thailand: Imperial Golden Triangle Resort Hotel. p. 275-80. 